\title{
Investigate the Performance of Multiple Problem-Solving Strategies for the Unit of "Finding the Area by a Definite Integral"
}

\author{
M. Y. Ting
}

\begin{abstract}
Integration is an important topic in the mathematics curriculum, but students generally believe that it is difficult to cope with the challenges of solving integration problems. In order to accurately and efficiently solve integration problems, students need to develop problem-solving flexibility - they need to learn a variety of strategies, and to solve a particular problem, and how to choose the best among these strategies. In this study, multiple problem-solving strategies had been investigated by applying two patterns, the computerized assessment had been held in order to estimate the greatest possible performance of the students in the unit of finding area by integration. Eleven classes of students from an unnamed university were chosen as samples of this study. This study would compare different problem-solving strategies and hope to help the students to have a broader learning. They were divided into three groups, in which the first answered all items with the preferred strategy, the second answered half the items with the preferred strategy and the third was not instructed to use any particular strategy. After the computerized test, it was found that. Group 1 performed better on the test overall. This study also conducted the simulations to confirm the group 1, who took the preferred strategy, had the best performance. It is hoped that the results of this research may assist as a reference to those teachers who are interested in them.
\end{abstract}

Index Terms-Definite integral, multiple problem-solving strategies, the knowledge structure, experts' knowledge structure, DINA, MS-DINA.

\section{INTRODUCTION}

Whatever method is used, a general dissatisfaction with the calculus course has emerged in various countries round the world in the last decade [1]. Students learn mathematics most effectively when they are given opportunities to investigate ideas and concepts through problem-solving and are guided carefully into an understanding of the mathematical principles involved [2]. In math, this strategy includes memorizing algorithms and performing computations that may be abstract and not understood by students [3]. Although integration is an important topic in the Additional Mathematics syllabus, students frequently encounter various difficulties while solving integral problems and find it difficult to cope with them [4]. To solve math problems accurately and efficiently, students need to develop flexibility: they need to learn multiple strategies, and how to choose among them in tackling a particular problem [5].

The National Council of Teachers of Mathematics lists

Manuscript received August 19, 2015; revised October 12, 2015.

$\mathrm{Mu}-\mathrm{Yu}$ Ting is with Center for General Education, Formosa University, Taiwan (e-mail: mwa@nfu.edu.tw). problem-solving as one of their requirements for students [6] Students need to learn that math and problem- solving go hand in hand, and this concept can be realized through a problem-solving approach to teaching mathematics [7]. Research indicates that when college freshmen solve problems of irregular shapes areas, we can obtain their answering information by constructed-response concepts. This study will focus on three multiple problem- solving strategies to discover which is best for students solving integration problems.

Mathematical problem-solving requires creativity [8]. When teaching problem- solving, learning needs to go beyond conceptual frameworks and become creative [9]. "Problem-solving means engaging in a task for which the solution method is not known in advance." However, all students need problem-solving skills [10]. "Fiddle" with a problem, try this-and-that-and-the-other, until eventually some of the ideas that did not work suddenly fit together to give the solution [8]. Therefore, the ability to solve problems must be included in the students' mathematics curriculum to help them acquire the skills that are necessary to solve problems. When students use different strategies to solve problems, teachers should be affirming and encouraging so that students will be more likely to adapt to the development of a diversified society.

\section{MATERIALS AND METHODS}

\section{A. Problem Solving}

The largest numbers of errors committed were technical errors which were primarily attributed to secondary school students' lack of conceptual and procedural understanding of integration [11]. Problem solving is recognized as an important life skill involving a range of processes including analyzing, interpreting, reasoning, predicting, evaluating and reflecting [12], [13]. For that reason educating students as efficient problem solvers is an important role of mathematics education [13], [14].

Students need to learn that math and problem solving go hand in hand and are not separate entities, and this can be realized through a problem solving approach to teaching mathematics [15].

Problem solving is recognized as an important life skill involving a range of processes including analyzing, interpreting, reasoning, predicting, evaluating and reflecting [12], [13]. For that reason educating students as efficient problem solvers is an important role of mathematics education [13], [14]. 
In the elementary school, students studied a regular pattern area such as a square, rectangular, triangular, circular, trapezoid; but how would students determine the area of an irregular graph? This study investigates the integral in order to solve the area problems of irregular shapes. In order to accurately and efficiently solve the area problems of irregular graphs, students need to develop problem-solving flexibility - they need to learn a variety of strategies, and to solve a particular problem, and how to choose the best among these strategies. Expert's knowledge structure

\section{B. Expert's Knowledge Structure}

In 2007, the Elementary Teachers' Federation of Ontario (ETFO) stated their goal of finding a better way to close the gaps in their students' mathematical knowledge. Bethany suggested a change from more traditional teaching strategies [16]. It was determined that the focus of this research was the exploration of multiple problem-solving strategies for integration problems, such as finding the area under a curve by means of a definite integral. The study was organized as follows: first, a literature review was conducted, and then four university teachers taught the definite integral in their Calculus course, a requirement for the freshmen of an unnamed university. The researchers then built an expert knowledge structure after analyzing the teachers' academic beliefs, teaching experiences and topic requirements for the students. This study collected open-ended test items based on the experts' knowledge structure. Every item is designed to examine only the concept related to one node of the expert's knowledge structure.

A paper-and-pen test was administered to 163 examinees chosen from the university. After examining their results, the researchers found eleven error patterns in solving definite integration problems. These items in this pre-trial were then revised to become more suitable, and eight constructed response items were designed.

Gagne (1977) [17] introduced a hierarchy concept network, known as a knowledge structure. As shown in Fig. 1, B $\rightarrow$ A notes the concept $\mathrm{B}$ is the prerequisite concept of $\mathrm{A}$. If an examinee mastered concept $A$, then all of its prerequisite concepts (for example, concept B D) will be considered to be understood by the examinee.

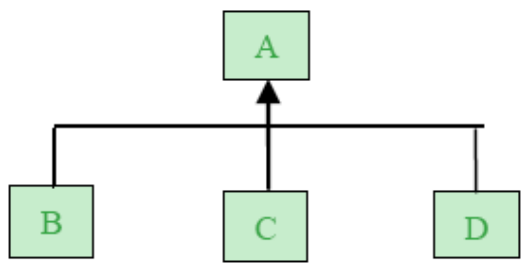

Fig. 1. The knowledge structure.

A knowledge structure was created by domain experts and practicing university teachers. The results from building an experts' knowledge structure are shown in Fig. 2.

\section{Content}

The teaching goals were further subdivided to diagnose whether the student has mastered the concept of multiple problem-solving strategies. The study mainly investigated the area enclosed by the line, and the parabola. Two problemsolving strategies, the vertical $d x$ pattern and the horizontal $d y$ pattern, are described as follows:

If $f$ and $g$ are two continuous real-valued functions defined on a closed interval $[a, b]$, and satisfy $f(x) \geq g(x)$, for every $x$ in $[a, b]$, then the area enclosed by two vertical lines $x=a, x$ $=b$, and two curves $y=f(x), y=g(x)$ is. As shown in Fig. 3 .


Fig. 2. Experts' knowledge structure.

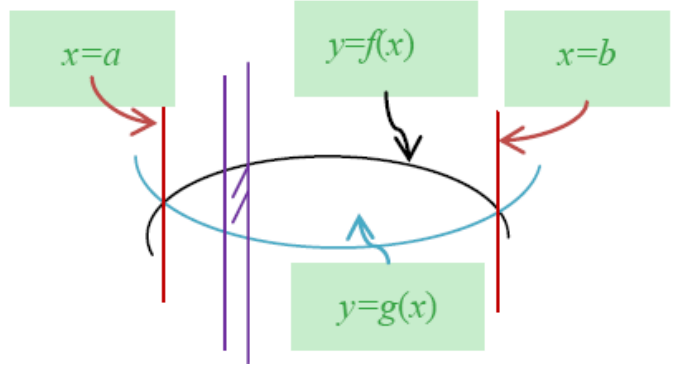

Fig. 3.The vertical $d x$ pattern.

If $F$ and $G$ are two continuous real-valued functions defined on a closed interval $[c, d]$, and satisfy $F(y) \geq G(y)$ for every $\mathrm{y}$ in $[c, d]$, then the area enclosed by two horizontal lines $y=c, y=d$, and two curves $x=F(y), x=G(y)$ is as shown in Fig. 4.

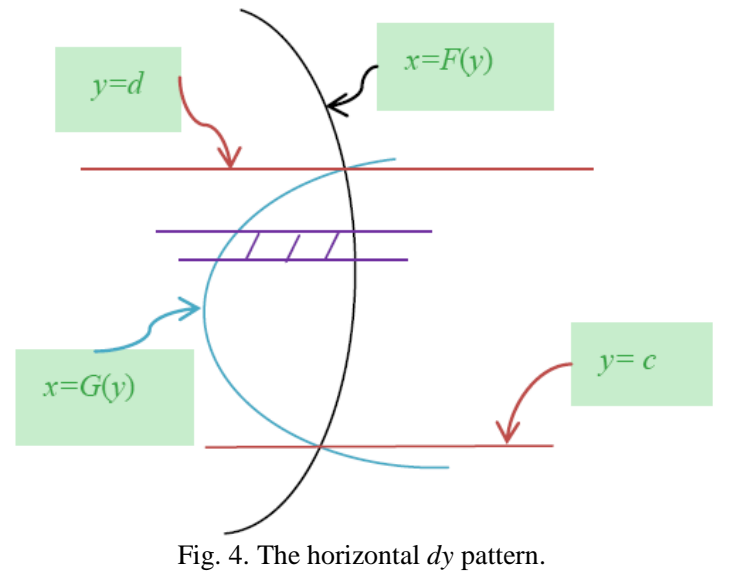

The study analyzed multiple problem-solving strategies with 578 valid samples of students, each restricted by time, manpower, material and other effects. Students refer the right explanations to construct the formulas and answers. The processes of answers will present at the bottom of the display area as shown in Fig. 5. The system will record the students' problem-solving processes in the database, as shown in Table 1 , where $\ulcorner$ int_ $\lrcorner$ represents the integral, $\left\ulcorner\{-2\}^{\wedge} 0\right\lrcorner$ represents -2 is the lower boundary and 0 is the upper boundary, $\ulcorner\wedge\lrcorner$ is a power of superscript symbol, $\ulcorner$ frac $\{a\}\{b\}\lrcorner$ is $a / b,\ulcorner f(x)$ $\left.I_{-}\{-2\}^{\wedge} 0\right\lrcorner$ is , such as students enter the database records as $\left\ulcorner\right.$ int_ $\{-2\}^{\wedge} 0\left(x^{\wedge} 3-4 x\right) \mathrm{dx}+$ int_0 $0^{\wedge} 2\left(4 x-x^{\wedge} 3\right) \mathrm{dx}=$ (frac $\left.\{1\}\{4\} x^{\wedge} 4-2 x^{\wedge} 2\right)\left.\right|_{-}\{-2\}^{\wedge} 0+\left(2 x^{\wedge} 2\right.$-frac $\left.\{1\}\{4\} x^{\wedge} 4\right)$ 
$\left.\mid 0^{\wedge} 2=8\right\lrcorner$ display area appears

$$
\int_{-2}^{0}\left(x^{3}-2 x\right) d x+\int_{0}^{2}\left(2 x-x^{3}\right) d x=\left.\left(\frac{x^{4}}{4}-x^{2}\right)\right|_{-2} ^{0}+\left.\left(x^{2}-\frac{x^{4}}{4}\right)\right|_{0} ^{2}=8
$$

Quiz screen are shown in Fig. 5.

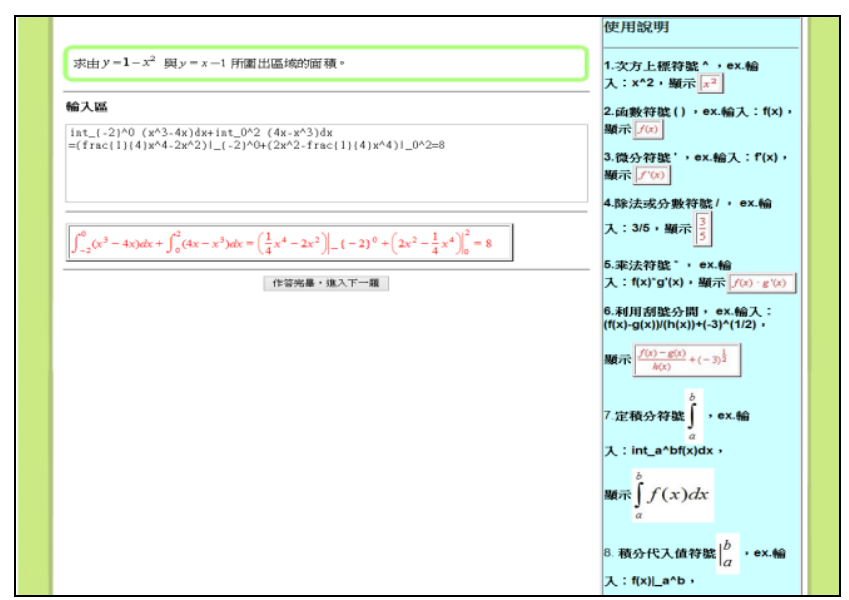

Fig. 5. Quiz screen.

There were three groups, as follows: in the first group, 270 examinees answered all items with the preferred strategy; in the second group, 41 examinees answered half the items with the preferred strategy (though in reality it was closer to four question); in the third group, 267 examinees were not instructed to use any particular strategy.

TABLE I: THE PARAdIGM OF STUDENT SOLVING- PROBLEM PROCESS RECORDED IN THE DATABASE

\begin{tabular}{ll}
\hline Serial number & Answer response \\
\hline \multirow{2}{*}{ w900231080001 } & $2 @ @$ int_ $\{-2\}^{\wedge} 0\left(x^{\wedge} 3-4 x\right) \mathrm{dx}+$ int_0^2 $2\left(4 x-x^{\wedge} 3\right)$ \\
& $\mathrm{dx}=\left.\left(\operatorname{frac}\{1\}\{4\} x^{\wedge} 4-2 x^{\wedge} 2\right)\right|_{-}\{-2\}^{\wedge} 0+\left(2 x^{\wedge} 2-\operatorname{frac}\{1\}\right.$ \\
& $\left.\{4\} x^{\wedge} 4\right) \mid{ }^{\wedge} 2=8$ \\
w900231080101 & $2 @ @$ int_ $\{-2\}^{\wedge} 2\left(4 x-x^{\wedge} 3\right) \mathrm{dx}=\left(2 x^{\wedge} 2-\operatorname{frac}\{1\}\{4\}\right.$ \\
& $\left.x^{\wedge} 4\right) \mid+\{-2\}^{\wedge} 2=0$ \\
\hline \hline
\end{tabular}

A computerized test was administered to examine 582 samples chosen from the university, although there were only 578 valid samples. Five hundred seventy-eight examinees were then divided into three groups to investigate the performance of multiple problem-solving strategies. Manual interpretation of the 578 samples indicated that each question had multiple problem-solving strategies. The first to fourth items had two problem-solving strategies each. The first item to the fourth item each have two problem-solving strategies. For example, the first question includes the first pattern,

$$
\int_{-2}^{2}\left(4-x^{2}\right) d x
$$

and the second pattern

$$
\int_{-3}^{1}[\sqrt{1-y}-(-\sqrt{1-y})] d y .
$$

The examinee responds to the first item with whether to choose the simple integrator. Item 5 to item 8 each have two problem-solving strategies. For example, the fifth question includes the first pattern,

$$
\int_{-2}^{1}\left[\left(1-x^{2}\right)-(x-1)\right] d x
$$

and the second pattern

$$
\int_{-3}^{0}[(y+1)-(-\sqrt{1-y})] d y
$$

The examinee responds to the fifth item with whether to use piecewise integrals conductive electrode of optoelectronic devices.

\begin{tabular}{|c|c|c|c|}
\hline & \multicolumn{3}{|c|}{ Estimated value } \\
\hline \multirow{3}{*}{ True value } & & Yes & No \\
\hline & Yes & $n_{11}$ & $n_{10}$ \\
\hline & No & $n_{01}$ & $n_{00}$ \\
\hline
\end{tabular}

\section{SimUlation}

Accuracy represents the consistency between the real value and the estimated value, as shown in Table II.

TABLE I: THE ARRANGEMENT OF CHANNELS

Note: $n_{i j}=1$, if the real value is in line with the estimated value, $n_{i j}=0$, otherwise.

The accuracy equals

$$
\left(n_{11}+n_{00}\right) / N
$$

where $N$ is the number of test data. This simulation identified accuracy as an indicator. The problem-solving strategies ( $d x$ pattern, $d y$ pattern, multiple problem-solving strategies) of two cognitive diagnostic models (1.deterministic input, noisy "and" gate mode (DINA); 2. multiple -strategy DINA model (MS-DINA))[18] for accuracy were investigated and simulated data generated using MATLAB software in this experiment.

\section{A. A Model of Single Problem-Solving Strategy - DINA}

$$
P\left(Y_{i j}=1 \mid \alpha_{i}\right)=\left(1-s_{j}\right)^{\eta_{i j}}\left(g_{j}\right)^{\left(1-n_{i j}\right)},
$$

where:

$i$ : examinee,

$j$ : item, $k$ : skill, ${ }_{\eta_{i j}}=\prod_{k=1}^{K} a_{i k}^{q_{j k}}$, slip: $s_{j}=P\left(Y_{i j}=0 \mid \eta_{i j}=1\right)$, guessing: $g_{j}=P\left(Y_{i j}=1 \mid \eta_{i j}=0\right)$,

$\eta_{i j}=\left\{\begin{array}{c}1, \text { the examinee } \mathrm{i} \text { masters all skills of problem } \mathrm{j} \\ \quad \text { solving strategy which has made correct answer. } \\ 0, \text { the examinee } \mathrm{i} \text { lacks at least one skill of problem } \mathrm{j} \\ \text { solving strategy which has made incorrect answer. }\end{array}\right.$

The problem-solving strategies ( $d x$ pattern, $d y$ pattern) of the cognitive diagnostic model (DINA) on the accuracy were investigated in this experiment. 


\section{B. A Model of Multiple Problem-Solving Strategies -} $M S$-DINA

$P\left(Y_{i j}=1 \mid \alpha_{i}, \omega_{i}\right)=\sum_{m=1}^{M} I\left[\omega_{i}=m\right]\left(1-s_{j m}\right)^{\eta_{i j m}}\left(g_{j m}\right)^{\left(1-\eta_{i j m}\right)}$

where:

$i$ : examinee.

$j$ : item.

$k$ : skill.

$m$ : strategy.

$$
\eta_{i j m}=\prod_{k=1}^{K} \mathbf{a}_{i k}^{q_{j k m}}
$$

slip: $s_{j m}=P\left(Y_{i j}=0 \mid \eta_{i j m}=1\right)$.

guessing: $g_{j m}=P\left(Y_{i j}=1 \mid \eta_{i j m}=0\right)$.

$\eta_{i j m}=\left\{\begin{array}{l}1, \text { when using strategy } \mathrm{m}, \text { the examinee i masters all } \\ \quad \text { skills of problem } \mathrm{j} \text { solving strategy which has made } \\ \quad \text { correct answer. } \\ 0, \text { when using strategy m,the examinee i lacks at least } \\ \quad \begin{array}{l}\text { one skill of problem } \mathrm{j} \text { solving strategy which has made } \\ \text { incorrect answer. }\end{array}\end{array}\right.$

The multiple problem-solving strategies of the cognitive diagnostic model (MS-DINA) on the accuracy were explored in this experiment.

Every simulation data variable and estimation in the experimental design were designed to imitate de la Torre (2008) [19], [20], as shown in Table III:

TABLE III: SiMULATION DATA VARIABLES

\begin{tabular}{lc}
\hline \hline Variable & Setting \\
\hline Sample size & 270
\end{tabular}

$\begin{array}{ll}\text { Attribute pattern } & \text { Alpha Uniform }(0,1) . \\ (\alpha) & \text { The mastery probability of each concept is } 0.5 \text { for } \\ & \text { every examinee. }\end{array}$

Model

DINA, MS-DINA

Number of replicates 20

$Q$ matrix represents that each exam item needs some specific strategies, if the $i$-th item requires the $j$-th strategy then $q_{i j}=1$, otherwise $q_{i j}=0 . Q$ matrix is defined as follows:

Define Q-matrix $=\left[q_{i j}\right]$,

$$
\begin{gathered}
q_{i j}=\left\{\begin{array}{l}
1, \text { the } i-\text { thitem requires the } j-\text { th strategy } \\
0, \text { otherwise }
\end{array}\right. \\
\text { where } i=1, \cdots, I, j=1, \ldots, J
\end{gathered}
$$

To investigate to use MATLAB software whether can work under the ideal condition, simulated data with $J=8, K=7$ and
$M=2$ were generated. To use the sample size was $N=270$ in generating the data. The experimental design Q-matrix as shown in Table IV. Last, the slip and guessing parameters were set to 0.10 for all items.

In the MS-DINA model $\left(M_{1}\right)$, all simulate examinees answered all items with the preferred strategy. The single problem-solving strategy $M_{2}$ and $M_{3}$ used the vertical $d x$

\begin{tabular}{|c|c|c|c|c|}
\hline & & $M S$ & & \\
\hline & & $M_{1}$ & $M_{2}$ & $M_{3}$ \\
\hline \multirow{2}{*}{$I_{1}$} & $S_{1}$ & 1 & 1 & 0 \\
\hline & $S_{2}$ & 0 & 0 & 1 \\
\hline \multirow{2}{*}{$I_{2}$} & $S_{1}$ & 1 & 1 & 0 \\
\hline & $S_{2}$ & 0 & 0 & 1 \\
\hline \multirow{2}{*}{$I_{3}$} & $S_{1}$ & 0 & 1 & 0 \\
\hline & $S_{2}$ & 1 & 0 & 1 \\
\hline \multirow{2}{*}{$I_{4}$} & $S_{1}$ & 0 & 1 & 0 \\
\hline & $S_{2}$ & 1 & 0 & 1 \\
\hline \multirow{2}{*}{$I_{5}$} & $S_{1}$ & 1 & 1 & 0 \\
\hline & $S_{2}$ & 0 & 0 & 1 \\
\hline \multirow{2}{*}{$I_{6}$} & $S_{1}$ & 1 & 1 & 0 \\
\hline & $S_{2}$ & 0 & 0 & 1 \\
\hline \multirow{2}{*}{$I_{7}$} & $S_{1}$ & 0 & 1 & 0 \\
\hline & $S_{2}$ & 1 & 0 & 1 \\
\hline \multirow{2}{*}{$I_{8}$} & $S_{1}$ & 0 & 1 & 0 \\
\hline & $S_{2}$ & 1 & 0 & 1 \\
\hline
\end{tabular}
and the horizontal $d y$ strategy respectively.

TABLE IV: THE EXPERIMENTAL DESIGN Q-MATRIX

Note: $I_{i}$ : the $i$-th question, $S_{1}$ : the vertical $d x$ Strategy, $S_{2}$ the horizontal $d y$ Strategy, $M S$ : multiple problem-solving strategy, S: single problem-solving strategy, $M_{k}$ : the $k$-th method

\section{Simulation Results AND Discussion}

Eleven classes of students from an unnamed university were chosen as samples of this study. They were divided into three groups, in which the first answered all items with the preferred strategy, the second answered half the items with the preferred strategy and the third was not instructed to use any particular strategy. After the computerized test, it was found that.

Group 1 performed better on the test overall. As long as the examinee had somewhere an error pattern, namely that he made this mistake. As long as the examinee performed a certain skill, namely that he mastered this concept. There were consistent problem-solving strategies among all questions.

We treated the last semester final scores as a covariate with the test scores as the dependent variable and performed an ANCOVA, yielding $P=0.279>0.05$. Thus, the test scores varied because the problem-solving strategies differed; therefore, post-hoc comparisons were performed on the values. It shows that Group 1 was best, followed sequentially by Group2, and Group 3.

The MS-DINA model $\left(M_{1}\right)$, estimated using the strategies of the real data, has a higher accuracy (0.7588) than the DINA model using $d x$ pattern $\left(M_{2}\right)(0.5523)$ or $d y$ pattern $\left(M_{3}\right)$ 
(0.5521). Multiple strategies are more in line with the actual state.

Empirical research and simulation are shown that using non-segmented integration strategy has the best performance achievements.

\section{CONCLUSION}

In this study, multiple problem-solving strategies were investigated by applying the vertical $d x$ pattern and the horizontal $d y$ pattern. A computerized assessment was conducted to estimate the greatest possible performance of the students in the unit of definite integrals. By doing so, we can presume that it is possible to give every student the critical thinking skills of mathematical concepts and understand the relationships between them. Using these skills, the students can develop good study habits and enhance their ability to learn mathematics. Furthermore, we encourage every student to continue engaging in creative challenges for all types of questions.

We hope that the students will think about their own development and progress, and enhance their creativity and ability to independently solve these problems. We also hope that teachers understand the benefits of problem-solving strategies for low- achieving students in remedial education. It is our goal to create a problem-solving learning environment to enhance students' problem-solving skills. It is hoped that the results of this research may assist as a reference to those teachers who are interested in them. Finally, the future research can be carried out for different subjects or different units.

\section{REFERENCES}

[1] D. Tall," Students' difficulties in calculus. Plenary presentation in working group 3," presented at ICME-7 1992, Québec, Canada, August 1992, pp. 13-28.

[2] Ontario Ministry of Education, The Ontario Curriculum Grades 1-8: Mathematics, Queen's Printer Ontario, Toronto, Canada, 2005.

[3] D. Rousseau, "Improving mathematical problem solving skills: The journey to success," in Pro Quest LLC, Chicago, Illinos, 2009.

[4] E. K. Seah, "Analysis of students' difficulties in solving integral problems," M.S. thesis, Dept Mathematics Education, Nanyang Technological University, 2003.

[5] J. Star. (2008). Developing flexibility in mathematical problem solving. [Online]. Available:
[6] Principles and Standards for School Mathematics, National Council of Teachers of Mathematics, VA: Reston, 2000.

[7] K. Hartweg and M. Heisler, "No tears here! Third-grade problem solvers," Teaching Children Mathematics, vol. 7, no. 6, pp. 362-368, March 2007

[8] J. H. Silverman, "An accompaniment to higher mathematics," The American Mathematical Monthly, vol. 106, no. 3, pp. 272-274, 1999.

[9] J. Schmittau, "Vygotskian theory and mathematics education Resolving the conceptual-procedural dichotomy," European Journal of Psychology of Education, vol. 19, no. 1, pp. 19-43, March 2004.

[10] R. L. E. Schwarzenberger, "The importance of mistakes: The 1984 presidential address," The Mathematical Gazette, vol. 68, no. 445, pp. 159-172, October 1984.

[11] E. K. Seah, "Analysis of students' difficulties in solving integration problems," The Mathematics Educator, vol. 9, no. 1, pp. 39-59, 2005.

[12] J. Anderson, "Mathematics curriculum development and the role of problem solving," Curriculum Studies Association National Biennial Conference, Australian, pp. 1-8, October 2009.

[13] I. Karatas; A. Baki, "The effect of learning environments based on problem solving on students' achievements of problem solving," International Electronic Journal of Elementary Education, vol. 5, no. 3, pp. 249-268, June 2013.

[14] J. Kilpatric, J. Swafford, and B. Findell, Adding It up: Helping Children Learns Mathematic, Washington, DC: National Academy Press, 2001.

[15] K. Hartweg and M. Heisler, "No tears here! Third-grade problem solvers," Teaching Children Mathematics, vol. 13, no. 7, pp. 362-368, March 2007.

[16] W. A. Kajander, D. Kerr, and J. Holm, "Uncertainty and the reform of elementary math education," ISRN Education, vol. 2013, p. 8, January 2013.

[17] R. M. Gagne, The Conditions of Learning, Holt, Rinehart \& Winston, New York, 1977.

[18] B. W. Junker and K. Sijtsma, "Cognitive assessment models with few assumptions, and connections with nonparametric item response theory," Applied Psychological Measurement, vol. 25, on. 3, pp. 258-272, September 2001.

[19] J. Torre and J. Douglas, "Model evaluation and multiple strategies in cognitive diagnosis: An analysis of fraction subtraction data," Sychometrika, vol. 73, no. 4, pp. 595-624, December 2008.

[20] J. Torre, "An empirically-based method of Q-matrix validation for the DINA model: Development and applications," Journal of Educational Measurement, vol. 45, no. 4, pp. 343-362, Winter 2008.

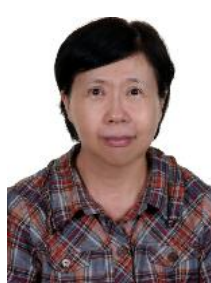

Mu-Yu Ting is currently an associate professor of Center for General Education at National Formosa University, Taiwan. She received her Ph.D. degree in Graduate Institute of Educational Information and Measurement from National Taichung University of Education, Taiwan. Her research interests include knowledge structure analysis, calculus teaching and dynamic assessment. 